\title{
Comprehensive Simulator Applied to Fluidized Bed Coal Gasification
}

\author{
Marcio L. de Souza-Santos* \\ State University of Campinas (UNICAMP), Faculty of Mechanical Engineering, Department of Energy, CP 6122, \\ Campinas, 13083-970 SP, Brazil
}

\begin{abstract}
A comprehensive simulator of fluidized bed equipment (CSFMB) has been able to reproduce experimental tests of bituminous coal gasification. The tests employed a bubbling fluidized bed pilot operating at atmospheric pressure and mixtures of air and steam were injected as gasification agents. Relatively low deviations between experimental and simulation results have been achieved. The simulator can now be applied on optimized scaling up of that equipment operating at any pressure. It also opens the possibility of integrating CSFMB as a module of wider simulations aiming optimizations of CIG/GT (Coal Integrated Gasification/Gas Turbine process) and Fisher-Tropsch processes.
\end{abstract}

Keywords: CSFMB, fluidized bed, coal, gasification.

\section{INTRODUCTION}

Coal is still an important source of energy and more efficient as well less pollutant processes are being developed. Among the most explored avenues is the CIG/GT (Coal Integrated Gasification/Gas Turbine) consisting on coal gasification to provide fuel gas free of tar that can be injected into gas turbines after proper cleaning to decrease concentrations of particles and alkaline. Another route for the utilization of gasification streams is the production of hydrocarbons through Fisher-Tropsch processes.

Several countries are investing in $R \& D$ of such technologies. The application of mathematical simulation saves a great deal of time and financial resources otherwise required if trial-and-error experimental search is used to find favorable process conditions. Once the simulator proved able to reproduce the experimental tests carried at pilots, it becomes a very important tool for optimized process scaling up.

Since its early versions, CSFMB (Comprehensive Simulator for Fluidized and Moving Beds) ${ }^{1}$ has been able to predict the behavior of bubbling fluidized beds [1-4] and has recently been classified as comprehensive because it includes all sub-models related to combustion and gasification of solid fuels and allows detailed simulation of boilers and gasifiers [5]. It has lately been improved and expanded in order to simulate a wider range of operations, such as those taking place in circulating fluidized beds and moving bed equipment [6-9].

All versions [1-4, 6-9] have been able to account for the influence of coal reactivity based on the work of Kasaoka $e t$ al. [10]. Nonetheless, such procedure was limited to a range of fuels and good predictions might be difficult if available published reaction kinetics differ too much from the actually

*Address correspondence to these authors at the State University of Campinas (UNICAMP), Faculty of Mechanical Engineering, Department of Energy, CP 6122, Campinas, 13083-970 SP, Brazil; Tel: +55-19-35213278; Fax: +55-19-32893722; E-mail: dss@fem.unicamp.br, or dss@csfmb.com

${ }^{1}$ Also named CeSFaMB or previously CSFB; www.csfmb.com and www.cesfamb.com at play during the fuel processing. In such cases, the best alternative is to input the kinetic parameters of key reactions into the simulator data bank after laboratorial determinations. The latest software interface allows the user to calibrate CSFMB to simulate those particular cases by changing the reaction kinetics parameters.

On the aspect of pyrolysis, the new version is equipped with much more precise routines based on very sophisticated methods such as structural DISKIN (Distributed Energy Reaction Kinetics Model) [11, 12] and FG-DVC (Depolymerization-vaporization-crosslinking) [13,14].

\section{MATHEMATICAL MODEL}

The latest form of the mathematical model in which CSFMB is based upon is detailed described in the available literature [6]. A summary of the basic model assumptions and simulation strategy is presented in the Appendix.

\section{EXPERIMENTAL DATA AND COMPARISONS AGAINST SIMULATIONS}

Likewise any comprehensive simulator, CSFMB requires reliable and detailed description of reactor geometry as well information regarding rates and characteristics of injected gas streams and particulate solids fed into the gasifier. Among the experimental work found in the literature, the one carried at the National University of Colombia (UNC) fulfills such requirements [15].

The basic characteristics of the reactor are described in Table 1.

During the experiments, coal and limestone were fed into the bed and Tables $\mathbf{2}$ and $\mathbf{3}$ show their main properties.

Amid the tests described in the publication [15], the fundamental operational conditions of two extremes cases are shown in Table 4.

\section{Fuel Reactivity}

Earlier attempts of applying CSFMB to reproduce the tests carried at UNC were not successful, mainly due to the distinct reactivity of the feeding coal as well to limitations of 
Table 1. Gasifier Main Design Data

\begin{tabular}{|l|l|}
\hline BASIC CHARACTERISTIC & VALUE \\
\hline \hline Bed internal diameter & $0.220 \mathrm{~m}$ \\
\hline Freeboard internal diameter & $0.220 \mathrm{~m}$ \\
\hline Average bed dynamic height & $1.0 \mathrm{~m}$ \\
\hline Total internal height (bed plus freeboard) & $2.0 \mathrm{~m}$ \\
\hline Average operational pressure & $101.3 \mathrm{kPa}$ \\
\hline Position of fuel feeding (from the distributor) & $0.30 \mathrm{~m}$ \\
\hline Total thickness of reactor insulation & $0.20 \mathrm{~m}$ \\
\hline Insulation average thermal conductivity & $0.18 \mathrm{~W} \mathrm{~m} \mathrm{~K}^{-1}$ \\
\hline Thickness of distributor porous plate & $0.10 \mathrm{~m}$ \\
\hline Distributor average thermal conductivity & $0.50 \mathrm{~W} \mathrm{~m} \mathrm{~K}^{-1}$ \\
\hline Number of orifices in the distributor & 142 \\
\hline Diameter of orifices in the distributor & $1.0 \mathrm{~mm}^{-1}$ \\
\hline
\end{tabular}

Table 2. Characteristics of the Coal Fed to the Gasifier

\begin{tabular}{|c|c|}
\hline CHARACTERISTIC & VALUE \\
\hline \multicolumn{2}{|c|}{ Proximate analysis (w.b. \%) } \\
\hline Moisture & 2.6 \\
\hline Volatiles & 41.8 \\
\hline Fixed Carbon & 54.1 \\
\hline Ash & 1.5 \\
\hline \multicolumn{2}{|l|}{ Ultimate. analysis (\% d.b.) } \\
\hline $\mathbf{C}$ & 75.3 \\
\hline $\mathbf{H}$ & 5.4 \\
\hline $\mathbf{N}$ & 1.8 \\
\hline $\mathbf{O}$ & 15.6 \\
\hline $\mathbf{S}$ & 0.4 \\
\hline Ash & 1.5 \\
\hline HHV (d.b.) (MJ/kg) & 29.7 \\
\hline Particle app. density $\left(\mathrm{kg} / \mathrm{m}^{3}\right)$ & 1250 \\
\hline Particle true density $\left(\mathrm{kg} / \mathrm{m}^{3}\right)^{\mathrm{a}}$ & 2000 \\
\hline \multicolumn{2}{|l|}{ Particle size distribution $^{\mathrm{b}}$} \\
\hline Sieve opening $(\mathbf{m m})$ & Retained \% \\
\hline 1.412 & 1.08 \\
\hline 1.180 & 28.53 \\
\hline $\mathbf{0 . 8 5 0}$ & 12.70 \\
\hline 0.710 & 28.18 \\
\hline 0.595 & 10.90 \\
\hline 0.295 & 17.57 \\
\hline$<0.150$ & 1.04 \\
\hline
\end{tabular}

${ }^{a}$ Assumed value from usually found at the literature.

${ }^{b}$ Kindly provided by the Colombian team.
Table 3. Characteristics of the Sulfur Absorbent Fed to the Gasifier

\begin{tabular}{|c|c|}
\hline CHARACTERISTIC & VALUE \\
\hline \multicolumn{2}{|l|}{ Proximate analysis (w.b. \%) } \\
\hline $\mathrm{CaCO}_{3}$ & 99.2 \\
\hline $\mathrm{CaO}$ & 0.0 \\
\hline $\mathrm{CaS}$ & 0.0 \\
\hline $\mathrm{CaSO}_{4}$ & 0.4 \\
\hline $\mathrm{MgCO}_{3}$ & 0.4 \\
\hline Particle app. density $\left(\mathrm{kg} / \mathrm{m}^{3}\right)$ & 2300 \\
\hline Particle true density $\left(\mathrm{kg} / \mathrm{m}^{3}\right)^{\mathrm{a}}$ & 3000 \\
\hline \multicolumn{2}{|l|}{ Particle size distribution $^{\mathrm{b}}$} \\
\hline Sieve opening $(\mathbf{m m})$ & Retained \% \\
\hline 1.412 & 0.02 \\
\hline 1.180 & 0.08 \\
\hline 0.850 & 31.77 \\
\hline 0.710 & 22.97 \\
\hline 0.595 & 41.59 \\
\hline 0.295 & 2.40 \\
\hline$<0.150$ & 1.17 \\
\hline
\end{tabular}

${ }^{a}$ Assumed value from usually found at the literature.

${ }^{\mathrm{b}}$ Kindly provided by the Colombian team.

the simulator. CSFMB was unable to cope with conditions too near the minimum fluidization. As known, the rate of particle circulations in the bed is proportional to the distance between the actual superficial gas velocity and the respective one found at minimum fluidization. If the fluidization regime approached minimum fluidization, the circulation nears zero. Since the rate of heat transfer between particles and gases depends on the rate of particle circulations, the differential equations describing the energy balances $[1,2,6]$ would become very stiff. The present CSFMB version allows the user to choose various strategies for the numerical solution of differential equation systems, as listed in the International Mathematics and Statistic Library (IMSL), which are able to cope with stiff problems. In addition, earlier versions applied routines related to pyrolysis that were not precise enough to deal with a great variety of solid fuels. As mentioned before, this point has been significantly improved through the application of DISKIN $[11,12]$ and FG-DVC $[13,14]$ methods. Details can be found elsewhere [6]. It should be reminded that many fuels contain components that even at very low fractions, act as catalysts or poisons to various reactions [16]. The combination of such effects is also known as reactivity and should be understood apart from the aspects associated with resistances to mass transfers of gases through the ash layer and nucleus of reacting fuel particles [1-4, 6-9]. Reactivity can also be affected by chemical species of limestone or dolomite added to the bed. That is why different kinetics parameters can be found in the literature even for a 
Table 4. Main Operational Conditions During the Gasification Experiments

\begin{tabular}{|c|c|c|}
\hline $\begin{array}{c}\text { OPERATIONAL } \\
\text { CONDITION }\end{array}$ & $\mathbf{6}$ \\
\cline { 2 - 3 } & $2.222 \mathrm{E}-3$ & 16 \\
\hline \hline Rate of coal feeding $(\mathrm{kg} / \mathrm{s})$ & $6.083 \mathrm{E}-3$ & $1.833 \mathrm{E}-3$ \\
\hline Rate of air injection $(\mathrm{kg} / \mathrm{s})$ & $1.306 \mathrm{E}-3$ & $4.722 \mathrm{E}-3$ \\
\hline Rate of steam injection $(\mathrm{kg} / \mathrm{s})$ & 693 & $1.111 \mathrm{E}-3$ \\
\hline Temperature of air-steam injection $(\mathrm{K})$ & 628 \\
\hline Rate of sulfur absorb. feeding $(\mathrm{kg} / \mathrm{s})$ & $2.222 \mathrm{E}-3$ & $1.833 \mathrm{E}-3$ \\
\hline
\end{tabular}

Table 5. Composition (molar \%, d.b.) of Gas Produced During Experiments and Respective Simulation Results Obtained without any Correction

\begin{tabular}{|c|c|c|c|c|}
\hline \multirow[t]{3}{*}{ SPECIES } & \multicolumn{4}{|c|}{ TEST } \\
\hline & \multicolumn{2}{|c|}{6} & \multicolumn{2}{|c|}{16} \\
\hline & Exper. & Simul. & Exper. & Simul. \\
\hline $\mathrm{H}_{2}$ & 8.53 & 12.4522 & 10.10 & 15.0951 \\
\hline $\mathrm{H}_{2} \mathrm{~S}$ & n.d. & 0.0378 & n.d. & 0.0307 \\
\hline $\mathrm{NH}_{3}$ & n.d. & 0.3980 & n.d. & 0.4380 \\
\hline NO & n.d. & 0.0017 & n.d. & 0.0030 \\
\hline $\mathrm{NO}_{2}$ & n.d. & 0.0000 & n.d. & 0.0000 \\
\hline $\mathrm{N}_{2}$ & 60.37 & 58.5004 & 57.50 & 55.2467 \\
\hline $\mathrm{N}_{2} \mathrm{O}$ & n.d. & 0.0000 & n.d. & 0.0000 \\
\hline $\mathrm{SO}_{2}$ & n.d. & 0.0300 & n.d. & 0.0315 \\
\hline $\mathrm{CO}$ & 10.94 & 6.8901 & 11.36 & 7.5410 \\
\hline $\mathrm{CO}_{2}$ & 19.31 & 19.7454 & 20.27 & 20.1715 \\
\hline $\mathrm{HCN}$ & n.d. & 0.0007 & n.d. & 0.0007 \\
\hline $\mathrm{CH}_{4}$ & 0.84 & 0.8690 & 0.77 & 1.3802 \\
\hline $\mathrm{C}_{2} \mathrm{H}_{4}$ & n.d. & 0.0348 & n.d. & 0.0331 \\
\hline $\mathrm{C}_{2} \mathrm{H}_{6}$ & n.d. & 0.0256 & n.d. & 0.0181 \\
\hline $\mathrm{C}_{3} \mathrm{H}_{6}$ & n.d. & 0.0012 & n.d. & 0.0009 \\
\hline $\mathrm{C}_{3} \mathrm{H}_{8}$ & n.d. & 0.0012 & n.d. & 0.0012 \\
\hline $\mathrm{C}_{6} \mathrm{H}_{6}$ & n.d. & 0.0118 & n.d. & 0.0084 \\
\hline
\end{tabular}

single reaction $[1,2,6,7,10,17-20]$. If specific kinetics of key reactions is not available for a given fuel, the alternative is to calibrate the simulator based on data from, at least, one experimental test. The usefulness of a simulator would be assured if it is capable of reproducing other tests consuming the same fuel.

To illustrate the effect of reactivity, two cases among the tests carried at UNC [15] were simulated. The results related to composition of produced gas are presented in Table 5. It shows large deviations between simulation and real operation regarding concentrations of carbon monoxide and hy- drogen. Therefore, the reactivity of that Colombian (Titiribi) coal was considerably different from bituminous coals used as standards by CSFMB [1-4, 6-10, 17-20].

Many reactions might be affected under catalytic or poisoning actions of chemical species present in fuel ashes and other factors; among them, the shift reaction, or:

$$
\mathrm{CO}+\mathrm{H}_{2} \mathrm{O} \Leftrightarrow \mathrm{CO}_{2}+\mathrm{H}_{2}
$$

The relatively high concentration of hydrogen and low concentration of carbon monoxide obtained by simulation, led to the suspicion that poisoning substances to that reaction were present in the coal or in the sulfur absorbent fed into 
Table 6. Composition (Molar \%, d.b.) of Gas Produced During Experiments and Respective Simulation Results Obtained Using Modification on the Shift Reaction Coefficients

\begin{tabular}{|c|c|c|c|c|}
\hline \multirow[t]{3}{*}{ SPECIES } & \multicolumn{4}{|c|}{ TEST } \\
\hline & \multicolumn{2}{|c|}{6} & \multicolumn{2}{|c|}{16} \\
\hline & Exper. & Simul. & Exper. & Simul. \\
\hline $\mathrm{H}_{2}$ & 8.53 & 8.5892 & 10.10 & 10.0835 \\
\hline $\mathrm{H}_{2} \mathrm{~S}$ & n.d. & 0.0406 & n.d. & 0.0409 \\
\hline $\mathrm{NH}_{3}$ & n.d. & 0.4254 & n.d. & 0.4568 \\
\hline NO & n.d. & 0.0014 & n.d. & 0.0001 \\
\hline $\mathrm{NO}_{2}$ & n.d. & 0.0000 & n.d. & 0.0000 \\
\hline $\mathrm{N}_{2}$ & 60.37 & 62.1830 & 57.50 & 58.4383 \\
\hline $\mathrm{N}_{2} \mathrm{O}$ & n.d. & 0.0000 & n.d. & 0.0000 \\
\hline $\mathrm{SO}_{2}$ & n.d. & 0.0303 & n.d. & 0.0335 \\
\hline $\mathrm{CO}$ & 10.94 & 11.8294 & 11.36 & 16.9325 \\
\hline $\mathrm{CO}_{2}$ & 19.31 & 16.0440 & 20.27 & 13.1134 \\
\hline $\mathrm{HCN}$ & n.d. & 0.0010 & n.d. & 0.0011 \\
\hline $\mathrm{CH}_{4}$ & 0.84 & 0.7745 & 0.77 & 0.8407 \\
\hline $\mathrm{C}_{2} \mathrm{H}_{4}$ & n.d. & 0.0385 & n.d. & 0.0322 \\
\hline $\mathrm{C}_{2} \mathrm{H}_{6}$ & n.d. & 0.0273 & n.d. & 0.0171 \\
\hline $\mathrm{C}_{3} \mathrm{H}_{6}$ & n.d. & 0.0013 & n.d. & 0.0008 \\
\hline $\mathrm{C}_{3} \mathrm{H}_{8}$ & n.d. & 0.0014 & n.d. & 0.0011 \\
\hline $\mathrm{C}_{6} \mathrm{H}_{6}$ & n.d. & 0.0126 & n.d. & 0.0079 \\
\hline
\end{tabular}

the bed. According to Biba et al. [21], that reaction shows Arrhenius $^{2}$ pre-exponential value $\left(\mathrm{k}_{0}\right)$ around $2.78 \times 10^{3} \mathrm{~s}^{-1}$ and activation parameter $\left(\mathrm{T}_{\mathrm{e}}\right)$ equal to $1510 \mathrm{~K}$. A simulation trial setting the pre-exponential equals to $8.5 \times 10^{1} \mathrm{~s}^{-1}$ led to the results presented in Table 6.

Noticeable decreases on deviations between simulation and experimental results were achieved. Table 7 presents other simulation results against experimental determinations.

Such level of precision is considered reasonable enough for a first round of optimized scaling up of the process. However, proper laboratorial work to obtain main gasification kinetic as well pyrolysis parameters may be conducted in order to feed the simulator data bank and achieve even better reproductions.

\section{DISCUSSION}

Once the simulator proved to be capable of reproducing pilot operations, it becomes an important tool for deeper understanding of the many processes taking place inside the equipment. This knowledge allows to:
- Guide further pilot tests avoiding operational conditions that may damage the pilot or jeopardize the safety of operators.

- Test conditions not covered by the pilot.

- Optimize the process having in mind any desired objective.

- Develop the design of large industrial units.

Figs. (1 to 13) illustrate various operational aspects provided by CSFMB. Here Test 6 is used as example and all figures are plotted against the vertical direction or height with origin located at the fluidized bed base.

Fig. (1) demonstrates the almost constant average temperature throughout the bed $^{3}$. Nonetheless, within a good portion of the bed, the temperature of bubbles surpassed that average. This happens due to sudden combustion of fuel gases accumulated inside relatively cold bubbles after mass exchanges with the neighboring emulsion. For instance, Fig. (2) shows the increase of carbon monoxide concentration in the emulsion just before the peak of combustion (Fig. 1) in the bubble phase. The localized and fast consumption of that gas in the bubbles around the region of maximum tempera-

${ }^{3}$ Only few points representing the average temperature appear in the graph because most of them coincide with the emulsion gas temperature. 
Table 7. Various Simulation and Experimental Results

\begin{tabular}{|c|c|c|c|c|}
\hline \multirow{3}{*}{$\begin{array}{c}\text { CONDITION } \\
\text { or } \\
\text { INFORMATION }\end{array}$} & \multicolumn{4}{|c|}{ TEST } \\
\hline & \multicolumn{2}{|c|}{6} & \multicolumn{2}{|c|}{12} \\
\hline & EXPERIM. & SIMULAT. & EXPERIM. & SIMULAT. \\
\hline Average temperature in the bed $(\mathrm{K})$ & 1128 & 1110 & 1137 & 1053 \\
\hline Heating value of clean and dry gas $(\mathrm{MJ} / \mathrm{kg})$ & 2.37 & 2.23 & 2.79 & 2.97 \\
\hline Flow of (wet) gas (kg/s) & n.d. & $9.185 \mathrm{E}-3$ & n.d. & 7.391E-3 \\
\hline Flow of gas (dry) $\left(\mathrm{Nm}^{3} / \mathrm{s}\right)$ & $5.56 \mathrm{E}-3$ & $6.02 \mathrm{E}-3$ & $5.32 \mathrm{E}-3$ & $4.97 \mathrm{E}-3$ \\
\hline Entrained particles at freeboard top $(\mathrm{kg} / \mathrm{s})$ & n.d & $1.88 \mathrm{E}-4$ & n.d. & $1.71 \mathrm{E}-4$ \\
\hline Flow of tar leaving with gases $(\mathrm{kg} / \mathrm{s})$ & n.d. & $2.22 \mathrm{E}-6$ & n.d. & $3.42 \mathrm{E}-6$ \\
\hline Flow of particles discharged from the system $(\mathrm{kg} / \mathrm{s})$ & n.c. & $6.67 \mathrm{E}-4$ & n.c. & $4.83 \mathrm{E}-4$ \\
\hline Carbon conversion $(\%)$ & $\begin{array}{l}57.60 \\
\text { (n.c.) }\end{array}$ & 72.47 & $\begin{array}{l}69.2 \\
\text { (n.c.) }\end{array}$ & 76.15 \\
\hline $\mathrm{TDH}(\mathrm{m})$ & n.d. & 1.624 & n.d. & 1.509 \\
\hline Average residence time of particles in the reactor $(\min )^{\mathrm{a}}$ & n.d. & 162.7 & n.d. & 214.9 \\
\hline Mass held in the bed $(\mathrm{kg})$ & n.d. & 23.9 & n.d. & 26.1 \\
\hline Hot efficiency $(\%)$ & n.d. & 39.26 & n.d. & 46.23 \\
\hline Cold efficiency $(\%)$ & n.d. & 25.95 & n.d. & 33.87 \\
\hline Exergetic efficiency $(\%)^{\mathrm{b}}$ & n.d. & 24.52 & n.d. & 25.48 \\
\hline
\end{tabular}

n.c.: no clear base of computation. n.d.: not determined or reported. ${ }^{\mathrm{a}}$ based on feeding rate of fuel. ${ }^{\mathrm{b}}$ (rate of exergy leaving with the produced gas)/(total rate of exergy entering the gasifier).

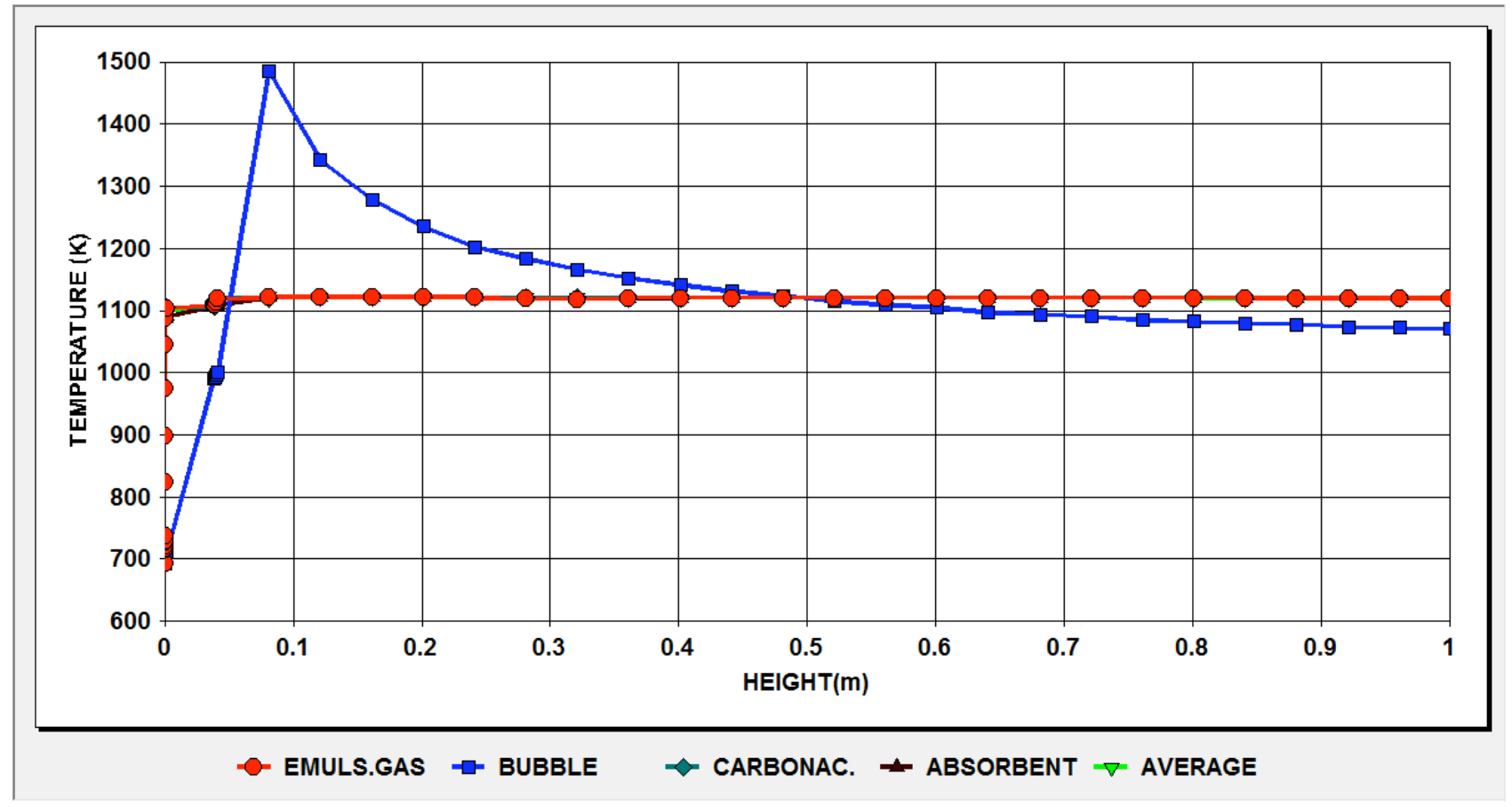

Fig. (1). Temperature profiles in the bed (Test 6). 


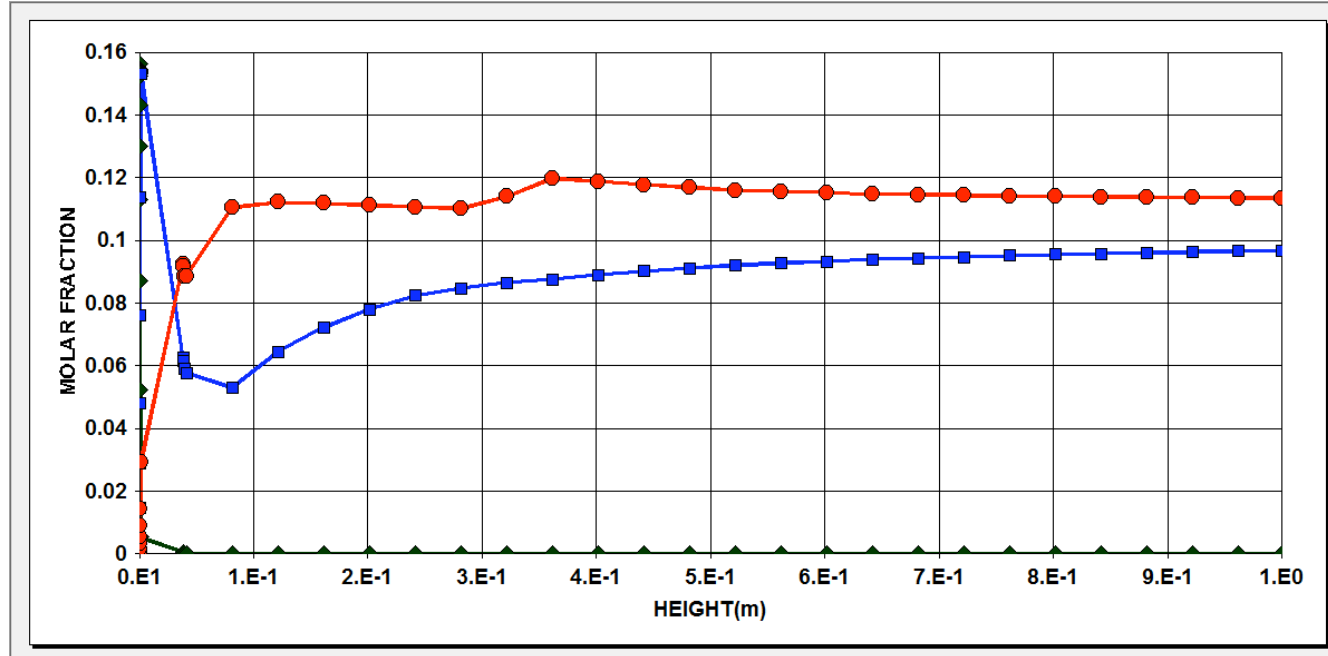

$\theta \mathrm{CO} 2 \rightarrow \mathrm{CO} \nrightarrow \mathrm{O} 2$

Fig. (2). Concentration profiles of $\mathrm{CO}, \mathrm{CO}_{2}$, and $\mathrm{O}_{2}$ in the emulsion phase (Test 6).

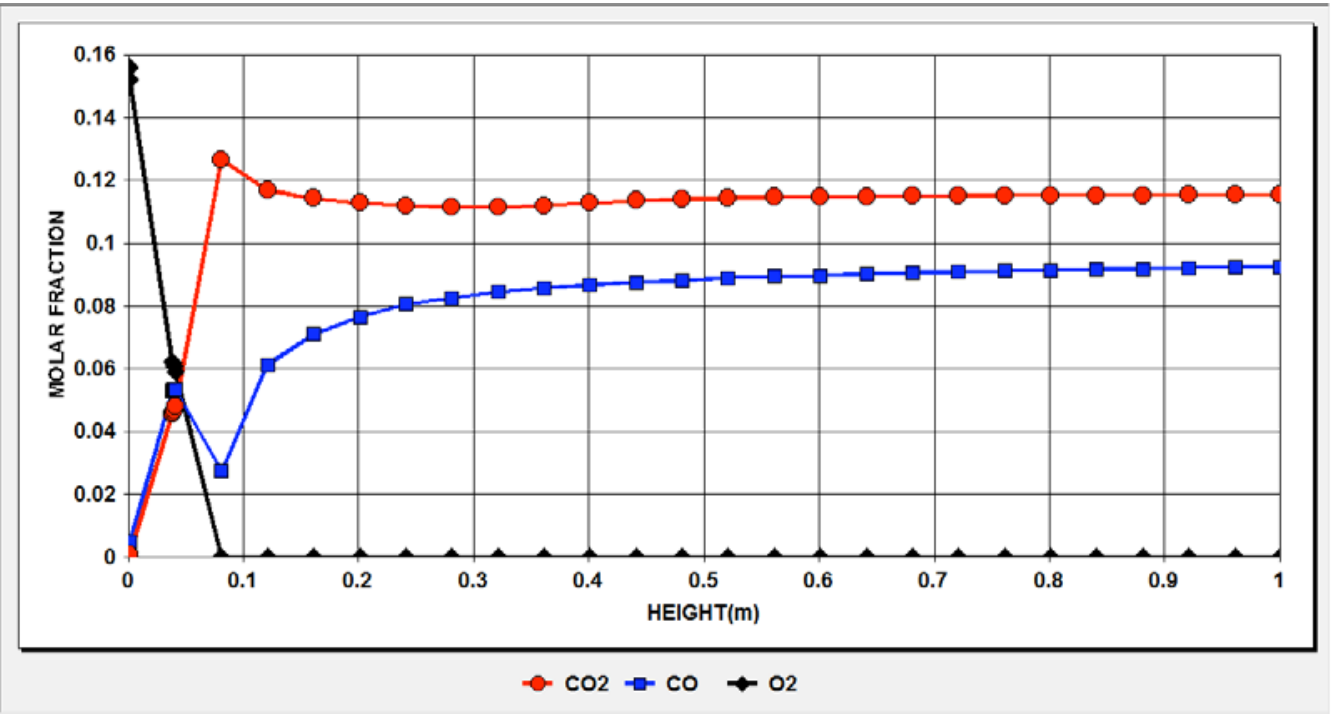

Fig. (3). Concentration profiles of $\mathrm{CO}, \mathrm{CO}_{2}$, and $\mathrm{O}_{2}$ in the bubble phase (Test 6).

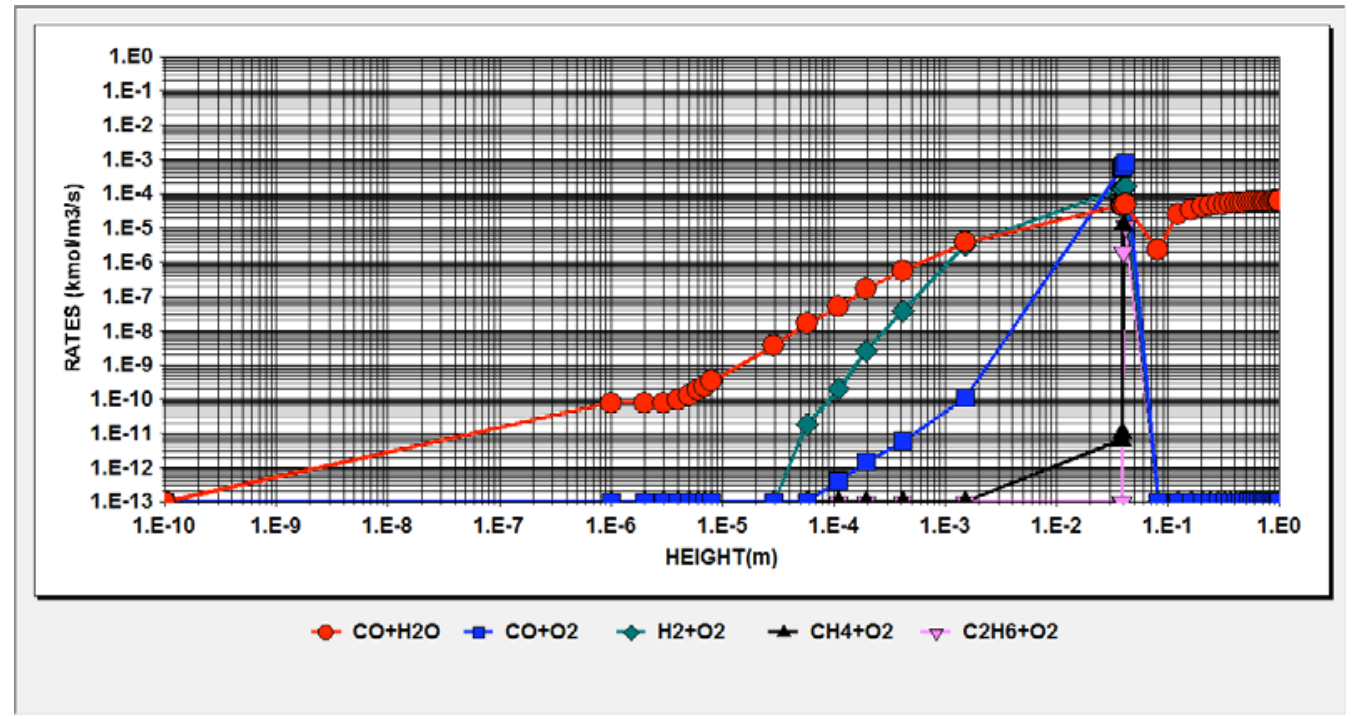

Fig. (4). Reaction rates of main homogeneous reactions in the bubble phase (log-log scale) (Test 6). 


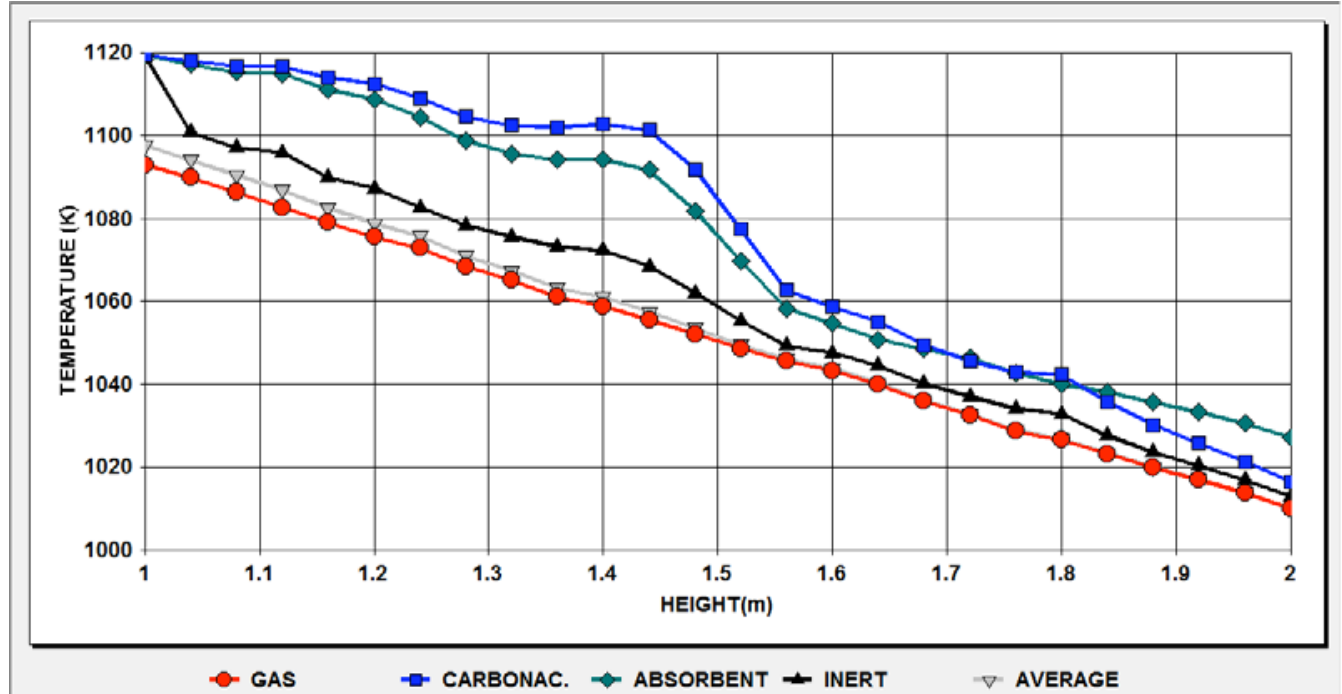

Fig. (5). Temperature profiles in the freeboard (Test 6).

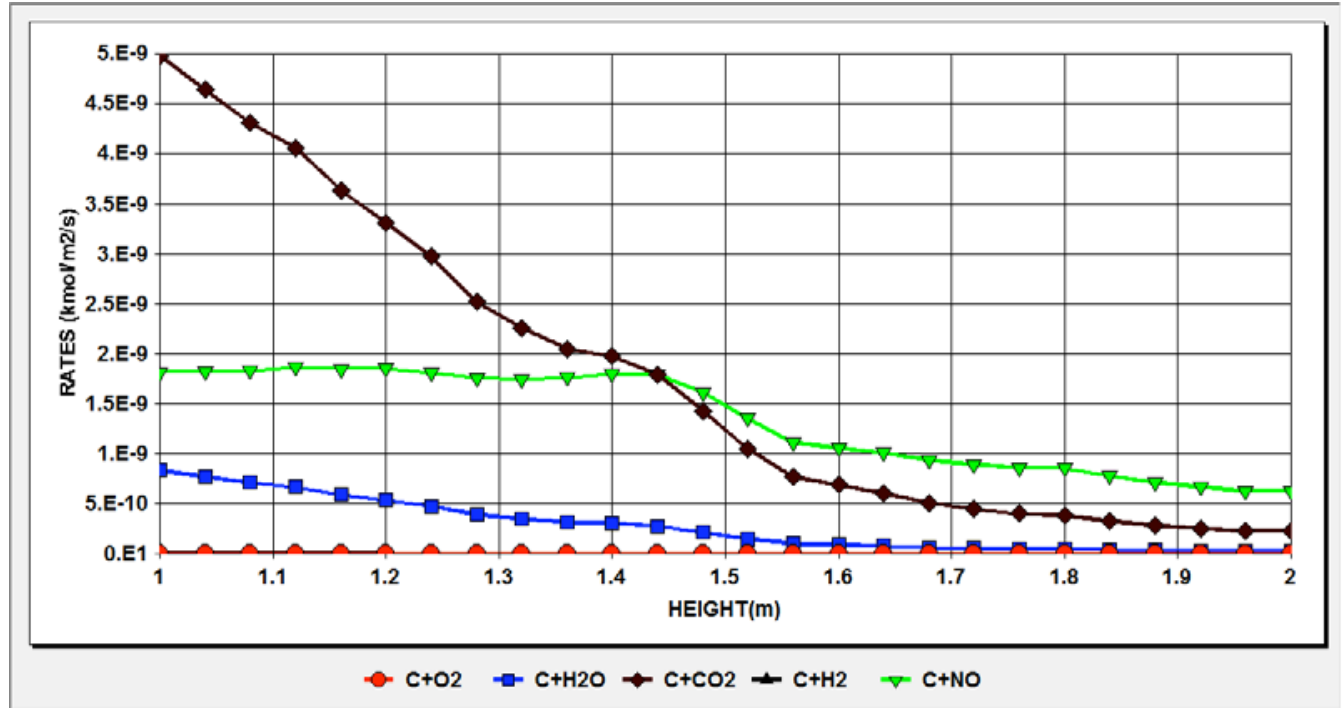

Fig. (6). Reaction rates of main heterogeneous reactions throughout the freeboard (Test 6).

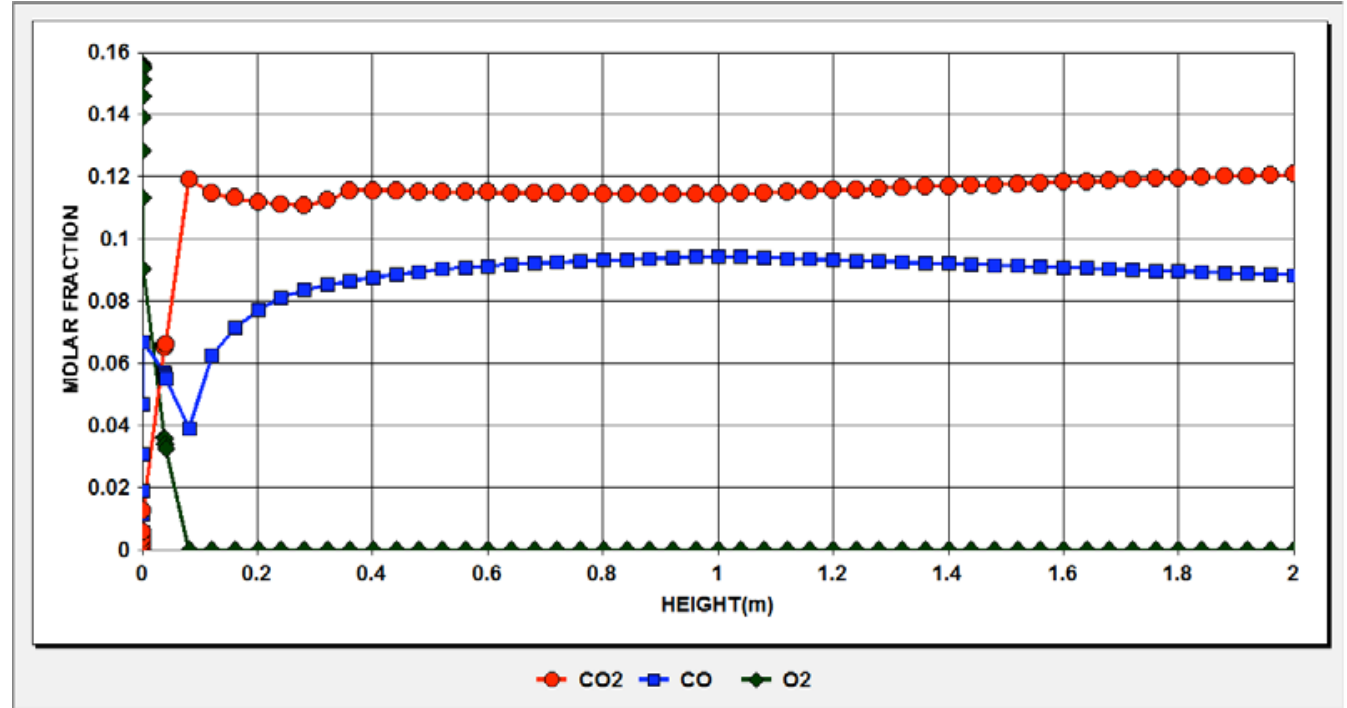

Fig. (7). Concentration profiles of $\mathrm{CO}, \mathrm{CO}_{2}$, and $\mathrm{O}_{2}$ throughout the reactor (Test 6). 


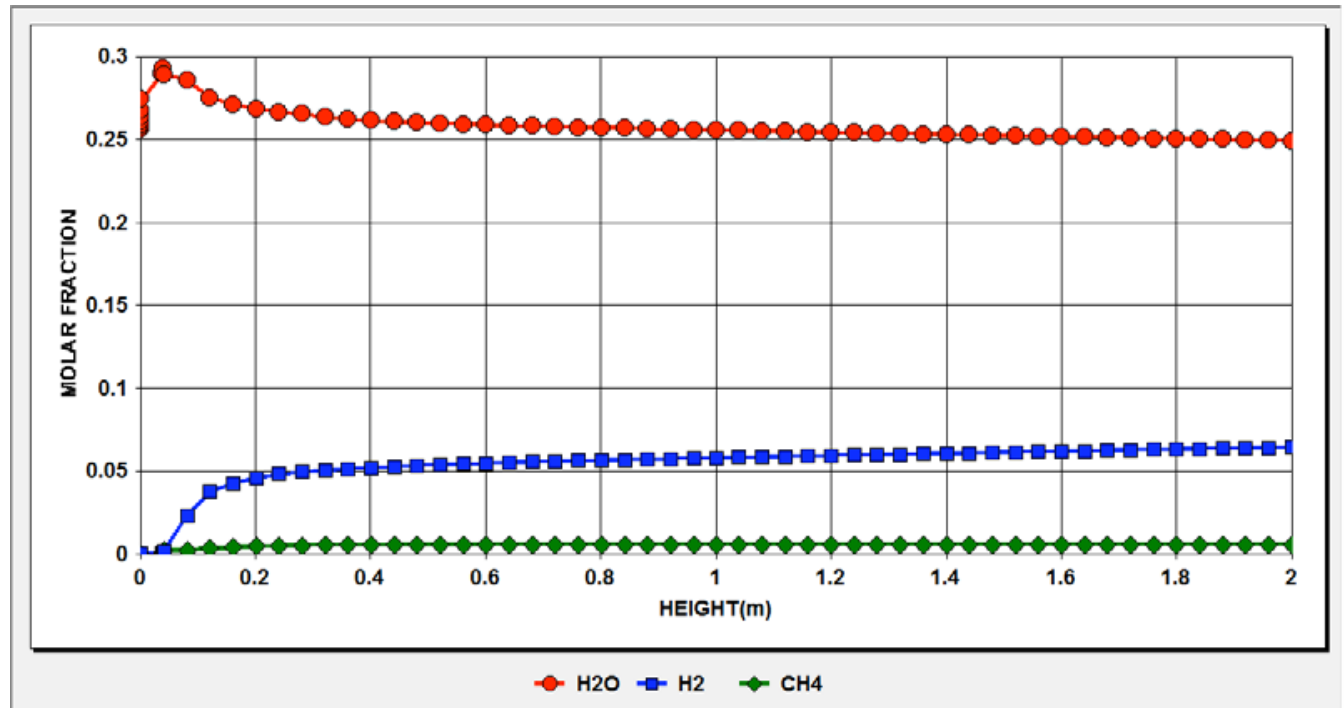

Fig. (8). Concentration profiles of $\mathrm{H}_{2}, \mathrm{H}_{2} \mathrm{O}$, and $\mathrm{CH}_{4}$ throughout the reactor (Test 6).

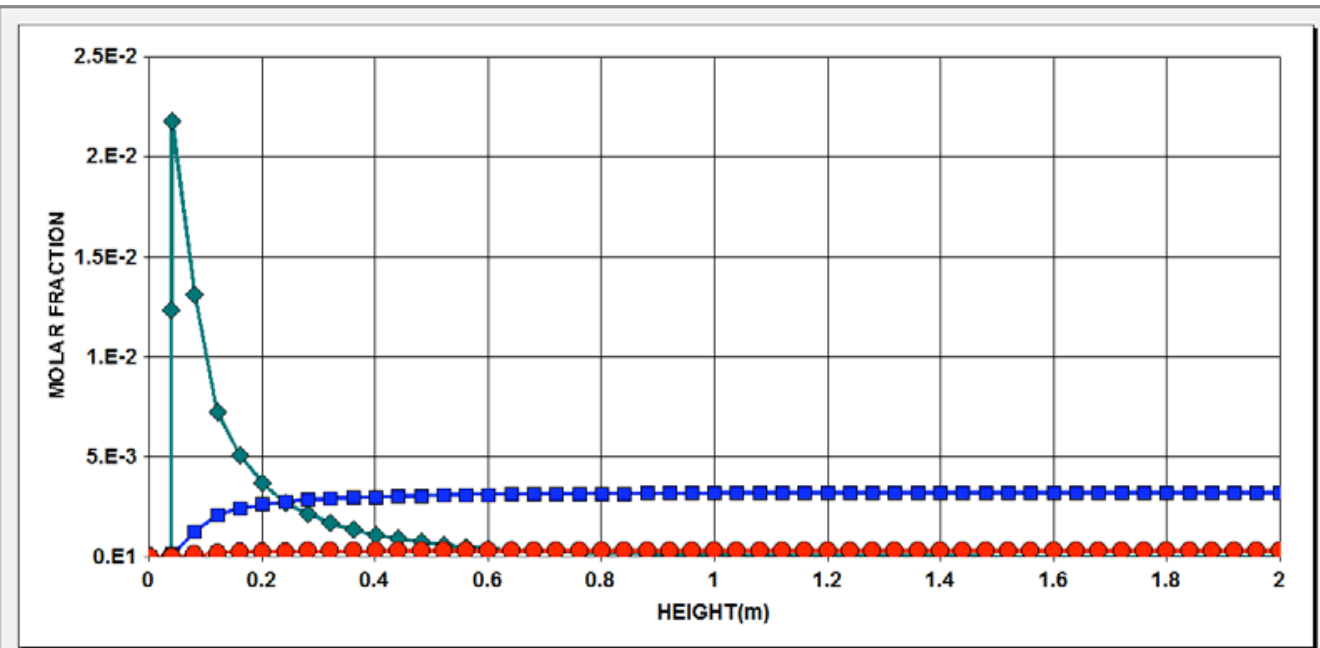

$\bullet \mathrm{H} 2 \mathrm{~S} \rightarrow \mathrm{NH3} \nrightarrow \mathrm{TAR} / \mathrm{OIL}$

Fig. (9). Concentration profiles of $\mathrm{H}_{2} \mathrm{~S}, \mathrm{SO}_{2}$, and Tar throughout the reactor (Test 6).

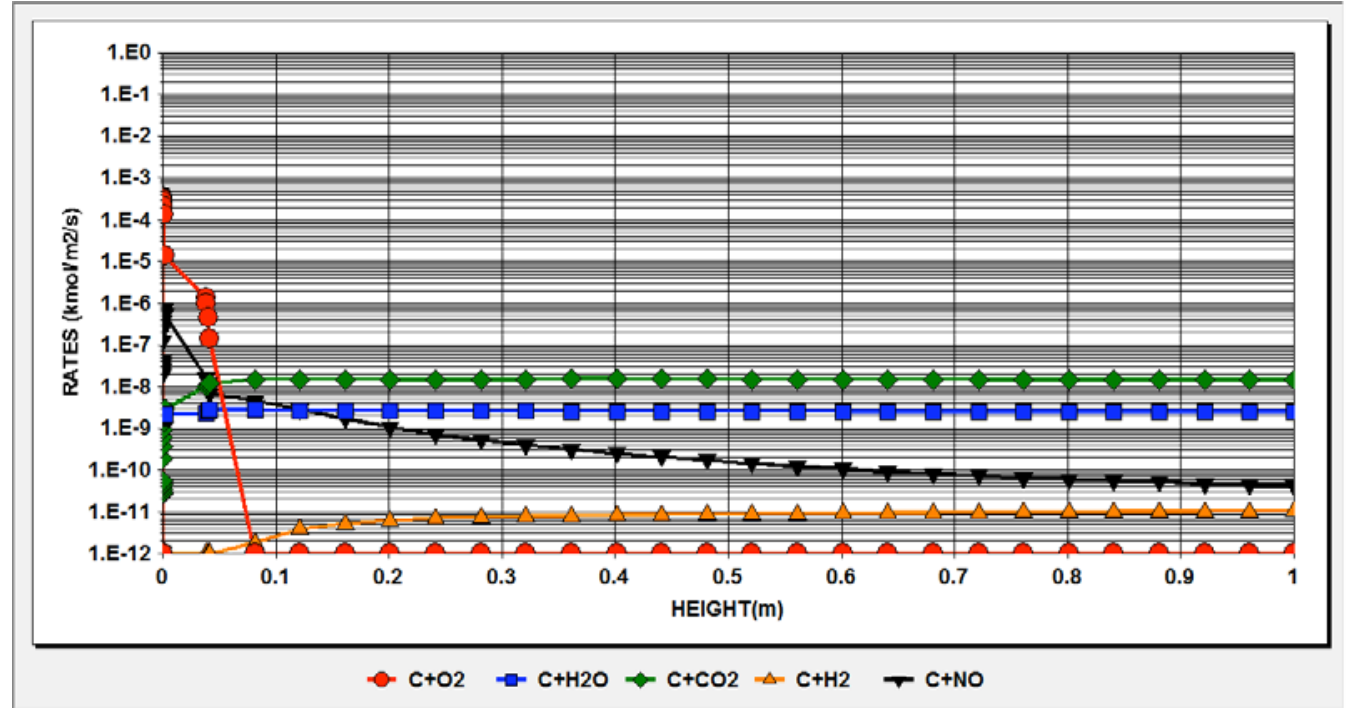

Fig. (10). Reaction rates of main heterogeneous reactions throughout the emulsion (Test 6). 


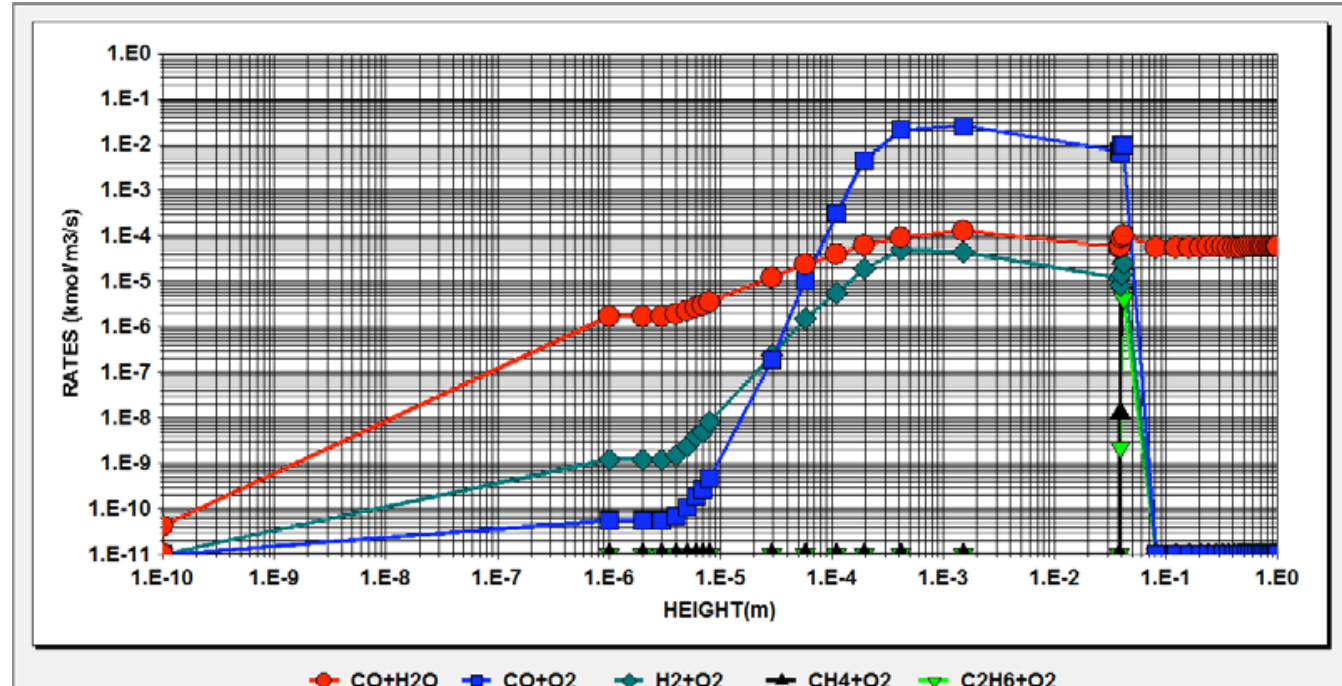

Fig. (11). Reaction rates of main homogeneous reactions throughout the emulsion (log-log scale) (Test 6).

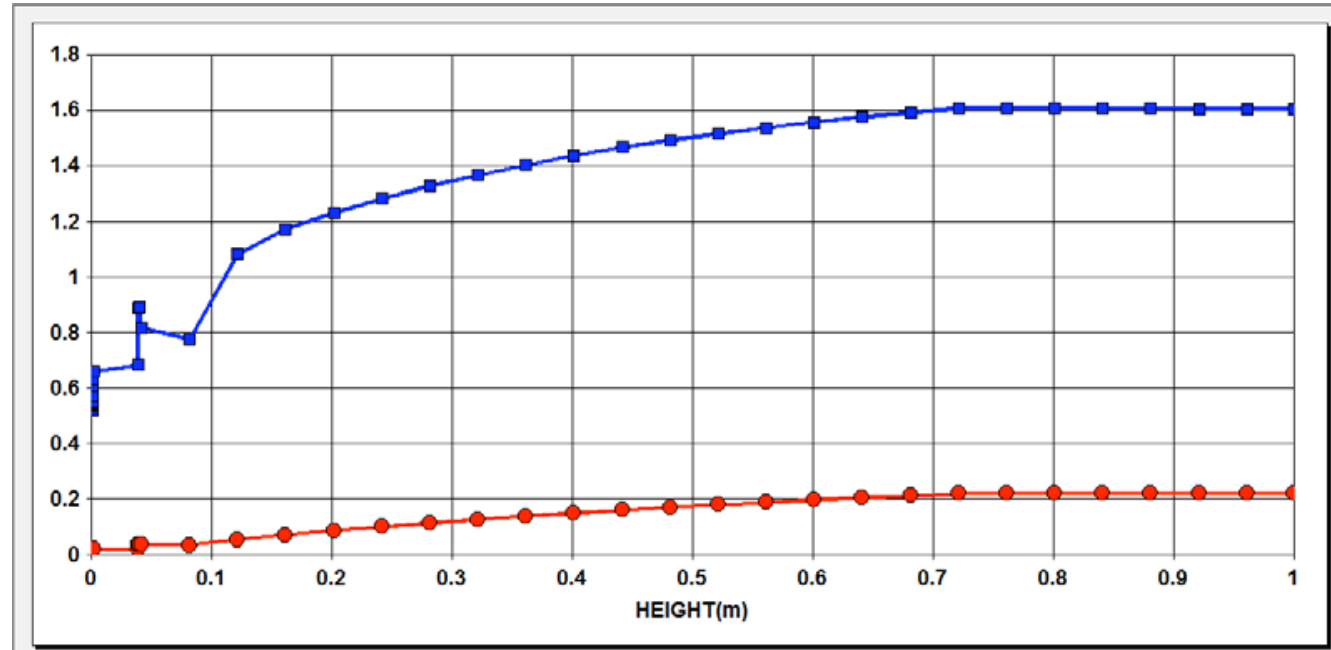

- Diameter(m) $\rightarrow \operatorname{Velocity}(\mathrm{m} / \mathrm{s})$

Fig. (12). Average bubble diameter and rising velocity along the bed (Test 6).

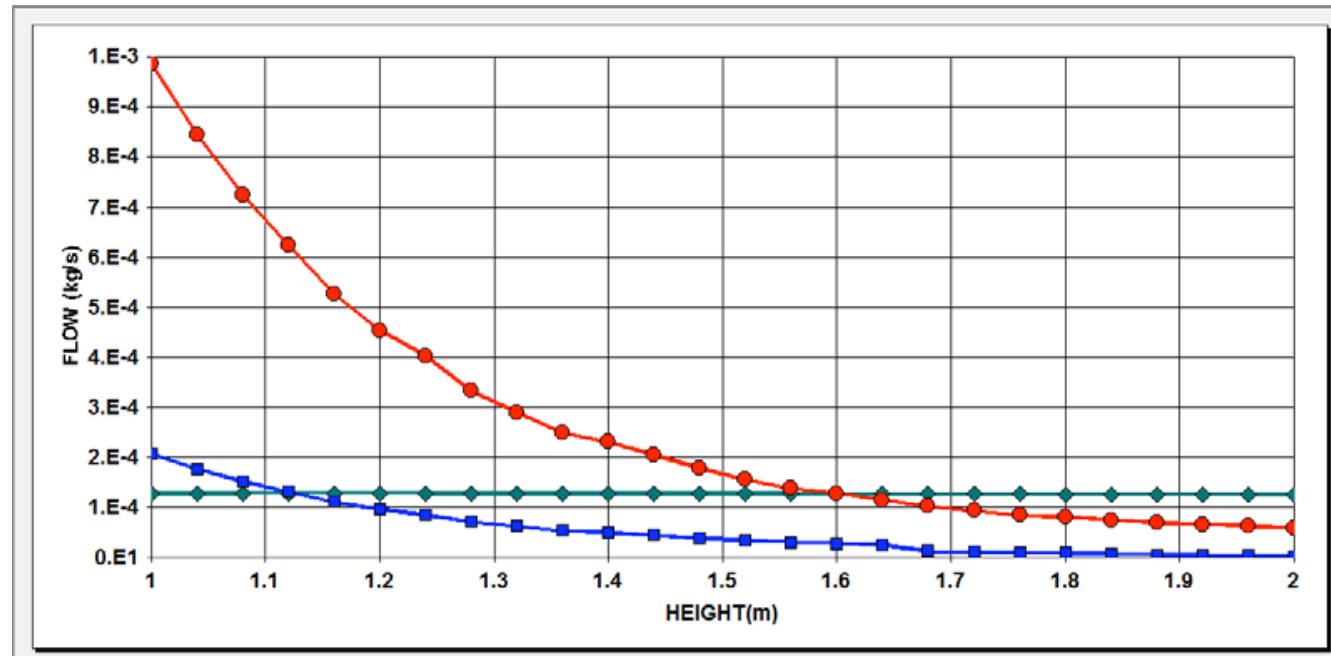

$\because$ CARBONAC. $\rightarrow$ ABSORBENT $\diamond$ INERT

Fig. (13). Upward flow of entrained particles throughout the freeboard (Test 6). 
ture is presented in Fig. (3). Among more than 90 reactions considered by the model [6-9], Fig. (4) shows the rates of most important homogeneous ones taking place in the bubble phase $^{4}$. It is interesting to notice that, among others, the important Shift Reaction $\left(\mathrm{CO}+\mathrm{H}_{2} \mathrm{O}=\mathrm{CO}_{2}+\mathrm{H}_{2}\right)$ keeps at relatively high rate during almost all length of the reactor. Therefore, showing that assumption of equilibrium, even at the gas exiting position at the reactor top, is far from reality.

Fig. (5) illustrates the steady decreases of temperatures in the freeboard upward direction. Such are due to endothermic gasification reactions. The rates of main heterogeneous reactions occurring in the freeboard are shown in Fig. (6). It shows that several important reactions continue with significant rates in that region.

Figs. (7 to 9) present the concentration profiles of main gases and tar throughout the reactor. As seen, the accumulation of fuel gases $\left(\mathrm{CO}, \mathrm{H}_{2}\right)$ is possible only at positions above the oxidizing region. In particular, Figs. (8 and 10) allows visualizing the correspondence between char-steam reaction and hydrogen production.

Fig. (9) shows the efficient destruction of tar-either by cracking or cooking - in the bed. Therefore, almost no tar is detected in the gaseous stream leaving the equipment. It is important to notice that enough residence time of tar fractions have been provided to its complete elimination inside the bed. This was possible because coal feeding was set at lower positions in the bed. On the other hand, such feeding should be placed above the oxidizing region to prevent the oxidation of valuable fuel gases released during the coal devolatilization. Figs. (2 to 4) reveal that oxidation occur until around $0.1 \mathrm{~m}$ above the distributor. Despite coal feeding at $0.3 \mathrm{~m}$, CSFMB demonstrates that particles going through devolatilization could be found for positions even below 0.1 $\mathrm{m}$. Thus, at least part of the fuel gases from coal pyrolysis was oxidized, therefore preventing higher gasification efficiencies to be achieved. CSFMB revealed that such a problem would be solved if the coal feeding were moved to $0.5 \mathrm{~m}$ above the distributor. For a scaling-up of the present unit, a combination of deeper beds and careful positioning of feeding point would provide higher gasification efficiencies than the achieved in during the tests at pilot-scale.

Fig. (11) shows the main homogeneous reaction in the emulsion. This logarithmic graph demonstrates how much faster the oxidation of coal is when compared with other reactions as well the extent of oxidizing region.

According to Fig. (12), simulation indicates that slugging-flow has probably occurred during Test 6 at positions near the top of the bed. It is important to stress that slugging flow decreases the mass transfer between emulsion and bubbles, therefore jeopardizing the efficiency of gasification. Such could be avoided by:

a) Decreasing the rate of air injection but maintaining the air-ratio by proportional decrease on coal feeding rate. Of course, the reduction of air injection should not compromise the minimum fluidization condition at any point in the bed.

${ }^{4}$ The legends are just reminder of each reaction. Their complete forms can be found elsewhere [1-8]. b) Increase the average size of particles fed into the bed. That would decrease the bubble sizes because a greater fraction of the injected gases would be diverted to emulsion in order to keep minimum fluidization condition at the bed basis $(\mathrm{z}=0)$.

The upward mass flow of particles through the freeboard is shown by Fig. (13). It is important noticing that inert particles are composed by ash detached from reacting coal particles $[1,2,6,7]$. That figure provides a clearer view on how the upward flow of large particle decreases throughout the freeboard while smaller particles maintain their flow rate. Such figures and computations allow proper design of gasifiers by showing when further increases in the freeboard height are not worthwhile or when the TDH (Transport Disengaging Height) is achieved.

\section{CONCLUSIONS}

The comprehensive simulator for fluidized bed (CSFMB) proved to be capable of providing good to reasonable reproduction of experimental tests of coal gasification.

The paper also shows how a simulation program can be calibrated to allow precise simulations.

At this stage, the results are already close enough to allow the use of CSFMB for at least a first round of optimized design of large scale coal gasification units.

\section{ACKNOWLEDGEMENTS}

The author is grateful for few additional details related to the experimental work provided by the teams at the National University of Colombia and University of Antioquia, in particular to Dr. Alonso Ocampo and Dr. Fanor Mondragon.

\section{NOMENCLATURE}

$$
\begin{aligned}
\mathrm{E} & =\text { activation energy }(\mathrm{kJ} / \mathrm{kmol}) \\
\mathrm{k}_{0} & =\text { pre-exponential kinetics parameter (unit depend } \\
& \text { on the reaction) } \\
\mathrm{R} & =\text { gas constant }\left(\mathrm{kJ} \mathrm{kmol}^{-1} \mathrm{~K}^{-1}\right) \\
\mathrm{T} & =\text { temperature }(\mathrm{K}) \\
\mathrm{T}_{\mathrm{e}} & =\text { parameter }=\mathrm{E} / \mathrm{R}(\mathrm{K})
\end{aligned}
$$

\section{APPENDIX}

A summary of the basic assumptions of CSFMB model follows:

1) The unit operates in steady-state regime.

2) The equipment is separated in two main regions: bed (or dense region in cases of circulating beds) and freeboard (or lean region for circulating class equipment).

3) The bed is divided in two main phases: bubble and emulsion.

4) There are three possible solid phases: fuel, inert, and sulfur absorbent such as limestone, dolomite or mixture of those. Ash, eventually detached from the spent fuel, would constitute part of the inert solid phase.

5) The emulsion is composed by solid particles and percolating gas. 
6) Despite the fast fluidization regimes found in circulating beds, the contributions for gas-solid reactions from particles in the bubbles are neglected. Future versions may drop this simplification.

7) Emulsion gas is considered inviscid, therefore rises through the bed in a plug-flow regime.

8) The same as above is assumed for the bubble gas. However, dimensions, raising velocity, fraction of bed volume occupied by bubbles, as well other characteristics of bubbles are considered in all calculations regarding that phase.

9) Bubbles and emulsion exchange mass and heat.

10) Heat transfers also occur between all phases, including particles.

11) Gases are assumed transparent regarding radiative heat transfers.

12) Emulsion gas exchanges heat with the vessel or reactor walls. Therefore, all heat transfers between the walls and other phases (bubbles and particles) take place indirectly through the emulsion gas.

13) All phases exchange heat with eventually immersed surfaces (such as tube banks) in the dense and lean regions.

14) Mass transfers occur between particles and emulsion gas as well between bubbles and emulsion.

15) An average uniform composition for each solid particle is computed in the bed through convergence procedures involving the solutions of differential mass and energy balances described elsewhere [6]. However, their composition may change in the freeboard. In addition, particles may present large gradients of temperature and composition in the bed and freeboard.

16) Compositions and temperatures of all gas and solid phases vary in the freeboard and are computed using complete differential and energy balances [6].

17) Particle size distributions modify due to chemical reactions, attritions between particles themselves, as well due to the entrainment and recirculation processes. All those are taken into account to compute the size distributions of each solid phase in the bed and freeboard.

18) Heat and mass transfers in the axial or vertical direction within each phase are considered negligible when compared with the respective transfers in the radial or horizontal direction between a phase and neighbouring ones.

19) At each axial position ( $\mathrm{z}$ ), mass transfers between phases result from differences of species average concentrations at each phase. As soon chemical species are consumed or formed by reactions, they are subtracted from or added to the respective phase. Therefore, these effects appear as sink or source terms in the mass continuity equations for each phase [6].
20) At each axial position ( $\mathrm{z}$ ), heat transfers between phases result from differences of temperature at each phase. These terms would appear as sinks or sources in the energy conservation equations [6].

21) At the basis of the dense region ( $\mathrm{z}=0)$, the two-phase model [6] is applied to determine the splitting of injected gas stream between emulsion and bubble phases.

22) For points above that $(z>0)$, the mass flow in each phase is determined by fundamental equations of transport phenomena. Those include mass transfers between the various phase as well homogeneous and heterogeneous reactions.

23) Boundary conditions for the gas phases concerning temperature, pressure and composition at $(\mathrm{z}=0)$ are given by the values of injected gas stream.

24) At each iteration, boundary conditions for the three possible solid phases (carbonaceous, sulfur absorbent, and inert) are obtained after differential energy balances involving conduction, convection, and radiative heat transfers between the distributor surface and the various phases.

25) The solution of differential equations describing the energy and mass transfers proceed from the distributor $(\mathrm{z}=0)$ to the top of lean region $\left(\mathrm{z}=\mathrm{z}_{\mathrm{F}}\right)$. The values at the top of the bed $\left(\mathrm{z}=\mathrm{z}_{\mathrm{D}}\right)$ are used as boundary conditions for the bottom of freeboard.

26) An iterative process allows the determination of boundary conditions for the solid phases at $\mathrm{z}=0$. For the first iteration, a carbon conversion is assumed. After solving the system of coupled non-linear differential equations, the new carbon conversion is computed. Conversions of all other solid-phases components are computed as well.

27) The cyclone system is simulated and all characteristics of the collected particles are obtained. Those are used by the mass and energy balances during the next iteration.

28) Steps 24 to 27 are repeated until convergence regarding a weighted overall deviation is achieved. That weighing considers deviations between assumed and computed conversions of chemical species as well between assumed and computed heat transfers among phases and immersed surfaces in the bed and freeboard. This and the tight coupling of all chemical and physical phenomena involved in the equipment, ensures consistency regarding all mass and energy balances.

Once the simulation is concluded all internal and overall details of the equipment operation such as temperature, concentration, and all other variable profiles throughout the entire equipment, are printed. A new graphical interface facilitates the input of data for simulations as well consultation and study of outputs.

As seen above, despite taking into account heat and mass transfer between phases in the radial or horizontal direction, all variations on temperatures and concentrations are assumed to occur only in the axial direction (z). Therefore, this 
is a one-dimensional model. Regardless of that apparent simplicity, the solution of governing non-linear and tightly coupled system of differential equations provides a complete and detailed picture of all significant aspects inside the equipment.

Fundamental as well auxiliary equations of that model are presented elsewhere [6].

\section{REFERENCES}

[1] M.L. de Souza-Santos, "Modelling and Simulation of FluidizedBed Boilers and Gasifiers for Carbonaceous Solids" Ph.D. thesis, University of Sheffield, Department of Chemical Engineer and Fuel Technology, United Kingdom, 1987.

[2] M.L. de Souza-Santos, "Comprehensive Modelling and Simulation of Fluidized-Bed Boilers and Gasifiers", Fuel., vol. 68, pp. 1507$1521,1989$.

[3] M.L. de Souza-Santos, "Application of Comprehensive Simulation to Pressurized Fluidized Bed Hydroretorting of Shale", Fuel., vol. 73, pp. 1459-1465, 1994.

[4] M.L. de Souza-Santos, "Application of Comprehensive Simulation of Fluidized-Bed Reactors to the Pressurized Gasification of Biomass", J. Brazil. Soc. Mech. Sci., vol. XVI, pp. 376-383, 1994.

[5] A. Gómez-Barea, B. Leckner, "Modeling of biomass gasification in fluidized bed", Prog. Energy. Combust. Sci., vol. 36, 4, pp. 44-509, 2010.

[6] M.L. de Souza-Santos, Solid Fuels Combustion and Gasification: Modeling, Simulation, and Equipment Operation. $2^{\text {nd }}$ ed., New York: CRC Press, 2010

[7] M.L. de Souza-Santos, "A new version of CSFB, Comprehensive Simulator for Fluidized Bed Equipment”, Fuel., vol. 86, pp. 16841709, 2007.

[8] M.L. de Souza-Santos, "Comprehensive simulator (CSFMB) applied to circulating fluidized bed boilers and gasifiers", Open Chem. Eng. J., vol. 2, pp. 106-118, 2008.
[9] M.L. de Souza-Santos, "CSFB applied to fluidized-bed gasification of special fuels", Fuel., vol. 88, pp. 826-833, 2009.

[10] S. Kasaoka, Y. Sakata, and C. Tong, "Kinetic evaluation of the reactivity of various coal chars for gasification with carbon dioxide in comparison with steam", Int. Chem. Eng., vol. 25, pp. 160-175, 1985.

[11] S. Niksa, and A.R. Kertein, "On the role of macromolecular configuration in rapid coal devolatilization", Fuel., vol. 166, pp. 13891399, 1987.

[12] S. Niksa, "Rapid coal devolatilization as an equilibrium flash distillation", AIChE J., vol. 34, pp. 790-802, 1988.

[13] P.R. Solomon, D.G. Hamblen, R.M. Carangelo, M.A. Serio, and G.V. Deshpande, "General model of coal devolatilization", Energy. Fuel., vol. 2, pp. 405-422, 1988.

[14] P.R. Solomon, D.G. Hamblen, R.M. Carangelo, M.A. Serio, G.V. Deshpande, "Models of tar formation during coal devolatilization", Combust. Flame., vol. 71, pp. 137-146, 1988.

[15] A. Ocampo, E. Arenas, F. Chejne, J. Espinel, C. Londono, J. Aguirre, J. Perez, "An experimental study on gasification of Colombian coal in fluidized bed", Fuel., vol. 82, pp. 161-164, 2003.

[16] K.H. van Heek, and H.J. Muhlen, "Kinetic studies of steam gasification of char in the presence of $\mathrm{H}_{2}, \mathrm{CO}_{2}$ and CO", Fuel., vol.64, pp.1405-1414, 1985

[17] L.D. Smoot, and D.T. Pratt DT, Pulverized-Coal Combustion and Gasification. New York: Plenum Press, 1979.

[18] L.D. Smoot, and P.J. Smith, Coal Combustion and Gasification New York: Plenum Press, 1985.

[19] L.D. Smoot, "General Characteristics of Coal," in: Pulverized-Coal Combustion and Gasification, L.D. Smoot, and D.T. Pratt, Ed. New York: Plenum Press, 1979.

[20] K.L. Smith, L.D. Smoot, T.H. Fletcher, and R.J. Pugmire, The Structure and Reaction Processes of Coal. New York: Plenum Press, 1994.

[21] V. Biba, J. Makac, E. Klose, and J. Malecha, Ind. Eng. Chem. Process Des. Dev., vol. 17, pp. 92-98, 1978.

(C) Marcio L. de Souza-Santos; Licensee Bentham Open.

This is an open access article licensed under the terms of the Creative Commons Attribution Non-Commercial License (http://creativecommons.org/licenses/by-nc/3.0/) which permits unrestricted, non-commercial use, distribution and reproduction in any medium, provided the work is properly cited. 